\title{
A study on clinical and echo cardiographic evaluation of neonatal cardiac murmurs and their follow up at 6 weeks of age
}

\author{
Saranya R. ${ }^{1}$, Sampath Kumar D. ${ }^{2}$, Shankar R. ${ }^{3}$ \\ ${ }^{1}$ Dr. Saranya Ravichandran, Assistant Professor, Department of Pediatrics, Vinayaka Mission Kirupananda Variyar \\ Medical College and Hospital Salem, ${ }^{2}$ Dr. Sampath Kumar Dhanaraj, Professor of Pediatrics, Govt Mohan \\ Kumaramangalam, Medical College and Hospital, Salem, ${ }^{3}$ Dr. Shankar Radhakrishnan, Associate Professor, Department \\ of Preventive Medicine, VMKVMCH, Salem, Tamil Nadu, India
}

Corresponding Author: Dr. Saranya Ravichandran, Assistant Professor, Department of Pediatrics, Vinayaka Mission Kirubanandha Variyar Medical College and Hospital Salem. Email id: drsaranpaeds86@gmail.com

\begin{abstract}
Background: The echocardiogram permits early accurate anatomical diagnosis either to reassure parents that the heart was normal, or to detect a heart disease and explain the nature of the abnormality and make an early referral for definitive treatment. Aim: Assessment of neonatal cardiac murmurs clinically and by echocardiogram at birth and at 6 weeks of age. Materials and Methods: A prospective longitudinal study was conducted on neonates for a period of one year at Government Mohan Kumaramangalam Medical College Hospital, Salem. Cardiac murmur was graded between 1 and 6 based on the intensity of the murmur. All neonates underwent an echocardiographic examination by Cardiologists at $1^{\text {st }}$ week and later at 6 weeks. Results: The incidence of murmur in the first week of life was 23/1000 live births and the incidence of congenital heart disease was 12.6/1000 live births and at 6 weeks it was 6.6/1000 live births. The most common congenital heart disease during the $1^{\text {st }}$ week examination was found to be VSD, followed by ASD and PDA. Identifying a pathological murmur and its association with structural congenital heart disease was found to be statistically significant $(\mathrm{p}<.05)$, whereas identifying an innocent murmur and its association with a normal heart did not show a statistical significance and so it infers that all the innocent murmurs has to be followed up with a echocardiogram to rule out structural heart disease in the neonates. Conclusion: It is important to evaluate all neonatal cardiac murmurs with echocardiogram before they become symptomatic.
\end{abstract}

Keywords: Congenital heart disease, Murmur, Echocardiogram

\section{Introduction}

Congenital heart disease is one of the most common congenital malformations. It remains the major cause of death in babies with congenital malformations. The most common presentations of the neonates with congenital heart disease are heart murmur, respiratory distress, cyanosis and congestive cardiac failure. They may also have abnormal chest x-ray and ECG findings. Congenital heart diseases account for about $10 \%$ of infant deaths and in that about half of the deaths are due to congenital malformations [1].

The estimated prevalence of CHD in the first 12 months was 6-8 per 1000 live births [2]. About $25 \%$ of CHDs are life-threatening and may manifest before the first routine clinical examination $[3,4]$. Failure to identify

Manuscript received: $4^{\text {th }}$ April 2018

Reviewed: $14^{\text {th }}$ April 2018

Author Corrected: $20^{\text {th }}$ April 2018

Accepted for Publication: $24^{\text {th }}$ April 2018 these critical lesions immediately after birth leads to increased mortality and morbidity [5]. The difficulties in detecting heart disease at neonatal examination are well known [6]. The neonatal examination takes place at a time of rapid change within the cardiovascular system as part of adaptation to extra uterine life [7]. These changes may produce murmurs which can be mistaken for heart disease [8]. Similarly, if transitional changes are slow to occur, presentation of congenital heart disease may be delayed.

Some murmurs in neonates, many in infants and most in childhood are 'benign' or 'innocent' $[9,10]$. The reported prevalence of murmurs in neonates varies from $0.6 \%$ to $77.4 \%$ [11]. Differentiation of such murmurs from those due to structural cardiac disease, so called 'pathological' murmurs, is largely clinical. Paediatricians are capable of differentiating one from 
the others, provided a detailed evaluation is done. Thus, detection of a murmur depends on the examiner's skill and experience, the timing and frequency of examination and the condition under which examination takes place. One of the major challenge in the management of congenital heart disease is its early diagnosis as very few validated investigatory tools being available.

Most babies presenting with an innocent heart murmur usually have a mid systolic ejection murmur which is of grade $1-2 / 6$ in intensity, located in the pulmonary area, radiates to the axillae and the back, and typically disappears by 3-6 months of age, which suggests that the origin is a branch of the pulmonary artery based on the hypothesis supported by clinical and angiographic studies [12]. However, not many studies had reported the echo cardiographic findings of newborn babies with an innocent heart murmur in the first days of life.

The echocardiogram permits early accurate anatomical diagnosis either to reassure parents that the heart was normal, or to detect a heart disease and explain the nature of the abnormality and make an early referral for definitive treatment.

Based on the echocardiography findings the neonates can be categorised as either having structural heart malformations; a physiological variant which would account for the murmur (such as left pulmonary artery branch stenosis or patent ductus arteriosus); a finding that in itself would not cause a murmur (such as cardiac hypertrophy secondary to maternal diabetes); or a completely normal echo-cardiogram [13].

\section{Aim}

Assessment of neonatal cardiac murmurs clinically and by echocardiogram at birth and at 6 weeks of age.

\section{Methodology}

Study design: Prospective longitudinal study

Study area: Government Mohan Kumaramangalam Medical College Hospital, Salem.

Study period: One year

Sample size: 98 neonates

Sampling: All babies born during the study period

Inclusion criteria: All term babies delivered in our hospital with cardiac murmurs on clinical examination were included in the study.
Exclusion Criteria: Preterm babies and all sick and moribund newborn babies who cannot be completely evaluated were excluded from the study. The study was conducted after getting the clearance from the institutional ethical committee and the informed consent from the parents of the newborn. Details of the neonates with precordial murmurs were taken into a structured data collection sheet which included socio-demographic variables such as maternal age, period of gestation, maturity and the sex of the baby, ethnicity and geographical area. Dysmorphology assessment of the neonate was done by history, physical examination of growth parameters, ectodermal features such as skin and hair, skull, face regions and overall face impression, hands and feet, joints and skeleton, and genitals and anus. Those with features suggestive of Down Syndrome (DS) were confirmed by karyotyping.

A thorough clinical examination was conducted which was later followed by ECG and Chest X-ray. Cardiac murmur was graded between 1 and 6 based on the intensity of the murmur. The intensity of the heart murmur was gauged using the system originally proposed by Levine [14]. Respiratory distress as defined as respiratory rate $>60 /$ min with chest wall recessions and grunting. Following which all neonates underwent an echocardiographic examination by Cardiologists. Echo included two-dimensional, Mmode, and Doppler measurement in the standard projections: subcostal view, four-chamber view, five chamber view, long- and short-axial parasternal views, and suprasternal view, with examination of the anatomy of the atriums, atrioventricular valves, ventricles, and septums. The semilunar valves, outflow tracks, and the great vessels were evaluated and flow in the ductus arteriosus examined-mode measurements were for evaluation of left and right ventricular dimensions, thickness and motion of the ventricular walls, left ventricular ejection fraction, and fractional shortening. Echocardiogram was performed initially at the $1^{\text {st }}$ week after birth and later during the follow-up visit at 6 weeks. Then neonates were then classified as having innocent murmur and structural heart defect and the structural heart defect was further subdivided into physiological variant or with significant heart disease.

Statistical Analysis: All data were entered and analysed by using SPSS version 21, for all the quantitative variables mean and standard deviation was derived and for all the non-parametric variables chisquare test was used for assessing the association between them considering $\mathrm{p}<.05$ as statistically significant. 


\section{Results}

The total number of live births occurred during the study period was 4116 and among them 98 neonates were found to have murmur during auscultation and only those 98 neonates were included in our analysis. Based on the neonates birth weight they were classified as appropriate for gestational age, small for gestational age and large for gestational age. The gender and birth weight wise distribution of the neonates was shown in table 1 . It is seen from the table that the male and female neonates were almost in equal number with a $\mathrm{M}: \mathrm{F}$ ratio of $0.9: 1$. More than $80 \%$ of the study subjects were appropriate for age and only $15 \%$ of the study subjects were small for gestational age and $3 \%$ were large for gestational age. The signs and symptoms for the neonates were assessed during the $6^{\text {th }}$ week of the follow-up period and the major symptoms were fast breathing and difficulty in feeding and the major sign was found to be respiratory distress and cyanosis (table 2). The presence of congenital heart disease was confirmed by echocardiogram. The association of grading of murmur and the presence of congenital heart disease was shown in table 3 . It is inferred from the table that as the grading of murmur increases the possibility of having congenital heart disease was found to be higher as there is a statistical significant association exist between the grading of murmur and the presence of CHD ( $\mathrm{p}<.05)$.

Based on the echocardiogram findings of the 98 neonates with murmur 52 of them were found to have a structural heart disease during the first week of examination and all the 98 neonates were asked to come for a follow-up visit at 6 weeks, in that out of 98 only 84 had come for the follow-up visit and among them 35 neonates were confirmed to have a structural congenital heart disease by performing a echocardiogram. The most common congenital heart disease during the $1^{\text {st }}$ week examination was found to be VSD, followed by ASD and PDA followed by cyanotic heart disease, physiological pulmonary stenosis and patent foramen ovale were found to be present in 6 and 2 neonates respectively. During the follow-up visit in the $6^{\text {th }}$ week both the patients with physiological pulmonary stenosis were found to become normal and out of 6 patients with patent foramen ovale 3 patients had become normal and one patient with cyanotis heart disease had died before the $6^{\text {th }}$ week (table 4). The various associated anomalies that were presented in patients with congenital heart disease were tabulated in table 5. Only 10 patients with CHD had an associated anomaly out of which Down's syndrome was present in two patients and the other anomalies were cleft lip, anal atresia, diaphragmatic hernia, etc. Among the various risk factors associated with CHD, consanguineous marriage, presence of CHD in mother, father or sibling found to have a statistical significant association with CHD whereas any type of chronic morbidities in the antenatal period like diabetes, hypertension, pre-eclampsia did not had a statistical significant association with the development of congenital heart disease (table 6). The association between presence of murmur and the congenital heart disease was shown in table 7. Identifying a pathological murmur and its association with structural congenital heart disease was found to be statistically significant $(\mathrm{p}<.05)$, whereas identifying an innocent murmur and its association with a normal heart did not show a statistical significance and so it infers that all the innocent murmurs has to be followed up with an echocardiogram to rule out structural heart disease in the neonates.

Table-1: Gender and birth weight wise distribution of the study subjects

\begin{tabular}{|c|c|c|c|c|}
\hline \multirow[t]{2}{*}{ Birth weight } & \multicolumn{2}{|c|}{ Gender } & \multirow[t]{2}{*}{ Total } & \multirow[t]{2}{*}{ P value } \\
\hline & Male & Female & & \\
\hline Appropriate for gestational age & $38(80.8 \%)$ & $42(82.3 \%)$ & $80(81.6 \%)$ & \multirow[t]{4}{*}{0.794} \\
\hline Small for gestational age & $8(17 \%)$ & $7(13.7 \%)$ & $15(15.3 \%)$ & \\
\hline Large for gestational age & $1(2.1 \%)$ & $2(3.9 \%)$ & $3(3 \%)$ & \\
\hline Total & $47(100 \%)$ & $51(100 \%)$ & $98(100 \%)$ & \\
\hline
\end{tabular}

$\mathrm{P}$ value derived by applying Chi-square test

Table-2: Distribution of the study subjects based on the symptoms and signs at 6 weeks of follow-up

\begin{tabular}{|c|c|c|c|}
\hline Symptoms & Frequency & Signs & Frequency \\
\hline Bluish discoloration of the body & $6(17.6 \%)$ & Cyanosis & $5(13.8 \%)$ \\
\hline Fast breathing & $16(47 \%)$ & Low oxygen saturation & $9(25 \%)$ \\
\hline Feeding difficulty & $9(26.4 \%)$ & Edema & $4(11.1 \%)$ \\
\hline Sweating & $3(8.8 \%)$ & Respiratory distress & $12(33.3 \%)$ \\
\hline \multicolumn{2}{|r|}{} & Bounding pulse & $6(16.6 \%)$ \\
\hline Total & $34(100 \%)$ & Total & $36(100 \%)$ \\
\hline
\end{tabular}


Table-3: Association of grading of murmur and presence of CHD based on echocardiogram.

\begin{tabular}{|c|c|c|c|}
\hline \multirow[t]{2}{*}{ Murmur } & \multicolumn{2}{|c|}{ Echocardiogram findings } & \multirow[t]{2}{*}{ P value } \\
\hline & CHD present & CHD absent & \\
\hline Systolic grade $1(n=4)$ & 0 & $4(100 \%)$ & \multirow[t]{6}{*}{$<.001$} \\
\hline Systolic grade $2(n=32)$ & $4(12.5 \%)$ & $28(87.5 \%)$ & \\
\hline Systolic grade $3(n=42)$ & $19(45.2 \%)$ & $23(54.7 \%)$ & \\
\hline Systolic grade $4(n=11)$ & $6(54.5 \%)$ & $5(45.4 \%)$ & \\
\hline Systolic grade $5(n=5)$ & $4(80 \%)$ & $1(20 \%)$ & \\
\hline Systolic grade $6(n=4)$ & $4(100 \%)$ & 0 & \\
\hline
\end{tabular}

$\mathrm{P}$ value derived by applying Chi-square test

Table-4: Types of congenital heart disease presented among the study subjects based on the echocardiogram findings at $1^{\text {st }}$ week and $6^{\text {th }}$ week

\begin{tabular}{|c|c|c|c|}
\hline CHD confirmed by ECHO & $1^{\text {st }}$ week $(n=98)$ & $6^{\text {th }}$ week $(n=84)$ & P value \\
\hline Normal & $46(46.9 \%)$ & $49(57.1 \%)$ & $<.01$ \\
\hline VSD & $12(12.2 \%)$ & $8(9.5 \%)$ & 0.0314 \\
\hline ASD & $9(9.1 \%)$ & $7(8.3 \%)$ & 0.318 \\
\hline Cyanotic heart disease & $6(6.1 \%)$ & $5(5.9 \%)$ & 0.981 \\
\hline PDA & $7(7.1 \%)$ & $3(3.5 \%)$ & $<.05$ \\
\hline PFO & $6(6.1 \%)$ & $3(3.5 \%)$ & $<.05$ \\
\hline ASD+PDA & $3(3 \%)$ & $3(3.5 \%)$ & 0.819 \\
\hline ASD+VSD & $2(2 \%)$ & $2(2.3 \%)$ & 0.791 \\
\hline $\begin{array}{c}\text { Physiological pulmonary } \\
\text { stenosis }\end{array}$ & $2(2 \%)$ & 0 & $<.05$ \\
\hline Mild TR & $2(2 \%)$ & $1(1.1 \%)$ & 0.918 \\
\hline ASD+TR & $1(1 \%)$ & $1(1.1 \%)$ & 0.991 \\
\hline VSD+PDA & $1(1 \%)$ & $1(1.1 \%)$ & 0.991 \\
\hline VSD+TR & $1(1 \%)$ & $1(1.1 \%)$ & 0.991 \\
\hline
\end{tabular}

P value derived by applying Chi-square test

Table-5: Distribution of the study subjects based on the presence of associated anomalies

\begin{tabular}{|c|c|c|}
\hline Associated anomaly & Frequency & Percentage \\
\hline No anomaly & 88 & $89.8 \%$ \\
\hline Absent radius & 1 & $1 \%$ \\
\hline Anal atresia & 1 & $1 \%$ \\
\hline Cleft lip & 1 & $1 \%$ \\
\hline Diaphragmatic hernia & 1 & $2 \%$ \\
\hline Downs syndrome & 2 & $1 \%$ \\
\hline Esophageal atresia & 1 & $1 \%$ \\
\hline Polydactyly & 1 & $2 \%$ \\
\hline Skin tag & 2 & $100 \%$ \\
\hline Total & 98 & \\
\hline
\end{tabular}


Table-6: Risk factors association between CHD among the study subjects.

\begin{tabular}{|c|c|c|c|}
\hline Risk factors & CHD present & Percentage & P value \\
\hline Consanguineous marriage (n=35) & 20 & $57.1 \%$ & $<.01$ \\
\hline CHD in mother $(\mathbf{n}=\mathbf{3})$ & 2 & $66.6 \%$ & $<.001$ \\
\hline CHD in father $(\mathbf{n}=\mathbf{2})$ & 1 & $50 \%$ & $<.01$ \\
\hline CHD in sibling (n=1) & 1 & $100 \%$ & $<.01$ \\
\hline $\begin{array}{c}\text { Morbidities in Antenatal period like diabetes, } \\
\text { hypertension, eclampsia etc }(\mathbf{n}=\mathbf{2 0})\end{array}$ & 3 & $15 \%$ & 0.518 \\
\hline
\end{tabular}

$\mathrm{P}$ value derived by applying Chi-square test

Table-7: Association between murmur and presence of CHD at $1^{\text {st }}$ and $6^{\text {th }}$ week among the study subjects

\begin{tabular}{|c|c|c|c|c|}
\hline \multirow{2}{*}{$\begin{array}{c}\text { Time of } \\
\text { examination }\end{array}$} & \multirow{2}{*}{$\begin{array}{c}\text { Clinical diagnosis of } \\
\text { murmur }\end{array}$} & \multicolumn{2}{|c|}{ Echocardiogram diagnosis } & \multirow[t]{2}{*}{ P value } \\
\hline & & Structural heart disease & Normal heart & \\
\hline \multirow[t]{2}{*}{$1^{\text {st }}$ week } & Pathological $(n=44)$ & $42(95.4 \%)$ & $2(4.5 \%)$ & $<.001$ \\
\hline & Innocent $(n=54)$ & $10(18.5 \%)$ & $44(81.4 \%)$ & 0.548 \\
\hline \multirow[t]{2}{*}{$6^{\text {th }}$ week } & Pathological $(n=40)$ & $30(75 \%)$ & $10(25 \%)$ & 0.0251 \\
\hline & Innocent $(n=44)$ & $6(13.6 \%)$ & $38(86.3 \%)$ & 0.683 \\
\hline
\end{tabular}

$\mathrm{P}$ value derived by applying Chi-square test

\section{Discussions}

Based on the results of the present study the incidence of murmur in the first week of life was 23/1000 live births and the incidence of congenital heart disease was $12.6 / 1000$ live births and at 6 weeks it was $6.6 / 1000$ live births. The overall percentage of structural heart disease among the neonates with murmur was $53.06 \%$. In our study population 80 neonates were appropriate for gestational age. 3 were LGA (large for gestational age) and 15 were SGA (small for gestational age).

AGA (appropriate for gestational age) is taken as reference category. There is no significant relationship between birth weight and CHD. This is similar to study done by Mehrdad Mirzharahimi M D [15]. Reports have shown that murmurs in the neonatal period had shown a varying incidence between $0.3-77.4 \%$ with incidence depending on various factors such as study size, auscultatory conditions and the skill of the examiner [11]. An Iranian study, within 24-hour neonatal examination among 2,928 neonates had revealed the prevalence of murmurs as 31 per 1,000 live births.

Furthermore, the same study had shown that the prevalence of cardiovascular malformations as 16 per 1,000 live births [15]. However not all neonates with congenital heart disease will be found to have a murmur during the immediate postnatal period check and similarly the vice versa, as most of the congenital heart disease remains asymptomatic in the early neonatal period [16]. History of consanguinity was present in parents of 23 newborns (23.4\%). History of CHD in family members is present in 11 newborns. When there is history of consanguinity in parents or history of CHD in family members there is three times more chance of getting CHD. Correlation between family history and CHD is significant. This is similar to studies by Becker $\mathrm{S} \quad \mathrm{M}$ and Ramegowda whose findings revealed increased incidence of CHD among babies of consanguineous parents $[17,18]$.

Neonates with murmur also had clinical feature which assisted in the classification of murmur as innocent or pathological. Clinical features suggestive of CHD are respiratory distress (most common finding), cyanosis, low oxygen saturation, edema and bounding peripheral pulses. 19 out of 52 babies with CHD had clinical features at birth. At 6 weeks of follow up neonates with positive clinical features in addition to murmur had persistent structural heart disease.

This correlation between clinical features and CHD at birth and at 6 weeks follow up was statistically significant. E. Clarke et al in their study suggested checking oxygen saturation in any neonate with suspicion of CHD [19]. Cyanosis can be easily missed. Some of the congenital anomalies, trisomies and dysmorphisms are seen in babies in the study. They are Down syndrome, neonate with absent radius, anal 
atresia, cleft lip, esophageal atresia with tracheoesophageal fistula, diaphragmatic hernia, polydactyly and skin tag. E. Clarke et al suggested to consider a murmur as pathological when it is associated with dysmorphic features [19]. In our study Chest X-ray showing cardiomegaly is taken as a positive finding and 10 out of 11 babies who had cardiomegaly were found to have structural heart disease. ECG abnormalities were found in 10 babies and in which 9 had structural heart disease.

In the study of Swenson JM et al chest X -ray and ECG helped in diagnosis of heart disease in 4 patients who were thought to have no heart disease [20]. They recommended ECG and Chest X -ray as valuable tools for heart disease evaluation.

A study conducted by Preethi S. Pillai etal in Kerala on 72 new-borns with murmur $75 \%$ had cardiac disease, of which $94.5 \%$ were acyanotic heart disease and $5.5 \%$ had cyanotic heart disease and the prevalence of cyanotic heart disease and acyanotic heart disease was almost similar to the present study and few other studies done in various other parts of the world had also shown an almost similar results [21-24]. Thus, a need for early assessment in neonates with murmurs has been recommended. In our study the most common structural heart disease was ventricular septal defect which is of muscular type and several other studies had also shown VSD as the most common congenital heart disease.

In the present study $13 \%$ of innocent murmur at $6^{\text {th }}$ week of follow-up was found to have structural heart disease which was almost in par with the results of the other studies $[25,26]$. Most of the babies $(75.5 \%)$ in our study had grade 2 or grade 3 murmur. This was in agreement with other studies [27]. There was a strong association between the degree of murmur and the significance of cardiac disease as none of the babies with Grade 1 or 2 murmurs had severe cardiac disease and most of the babies with grade 3,4 or 5 murmur had moderate to severe heart disease. In our study subjects none of the babies had a diastolic murmur. So it infers a skillful auscultation in recognizing a murmur in neonate is a mandate in routine neonatal examination.

\section{Conclusion}

Our study proves that the incidence of cardiac murmur is $23 / 1000$ live births and if a murmur is detected there is a $53 \%$ chance of having structural heart disease. $7.7 \%$ of our study subjects had severe form of cardiac disease. Hence it is important to evaluate all neonatal cardiac murmurs before they become symptomatic. Prompt early referral for echocardiography is necessary for diagnosis and appropriate management to reduce morbidity and mortality. Structurally normal heart in echocardiography helps in authoritative re-assurance of parents.

\section{Contribution by Authors}

- Dr. Saranya Ravichandran - Designing the whole study and examining the patients

- Dr. Sampath Kumar Dhanaraj - Writing the manuscript and examining the patients

- Dr. Shankar Radhakrishnan - Statistical analysis and deriving the statistical inference

What this study adds to existing knowledge: Referring the neonates with cardiac murmurs for echocardiogram at the earliest would prevent most of the morbidity and mortality due to cardiovascular diseases.

Funding: Nil, Conflict of interest: None initiated, Perission from IRB: Yes

\section{References}

1. Abu-Harb M, Hey E, Wren C. Death in infancy from unrecognized congenital heart disease. Arch Dis Child. 1994 Jul; 71 (1):3-7.

2. Hoffman JI, Kaplan S. The incidence of congenital heart disease. J Am Coll Cardiol. 2002 Jun 19;39 (12): 1890-900.

3. Wren C, Reinhardt Z, Khawaja K. Twenty-year trends in diagnosis of life-threatening neonatal cardiovascular malformations. Arch Dis Child Fetal Neonatal Ed. 2008; 93 (1):F33-F35. DOI: 10.1136/adc. 2007. 119032.

4. Richmond S, Wren C. Early diagnosis of congenital heart disease. Semin Neonatol. 2001 Feb;6(1):27-35.

5. Kuehl KS, Loffredo CA, Ferencz C. Failure to diagnose congenital heart disease in infancy. Pediatrics. 1999 Apr; 103 (4 Pt 1):743-7.

6. Abu-Harb M, Wyllie J, Hey E, Richmond S, Wren C. Presentation of obstructive left heart malformations in infancy. Arch Dis Child Fetal Neonatal Ed. 1994 Nov; 71 (3):F179-83.

7. Gandy GM. Examination of the neonate including gestational age assessment. In: Roberton NR, ed. Textbook of Neonatology. 2nd edn. Edinburgh: Churchilll Livinstone, 1992. 
8. Rudolph AM. The changes in the circulation after birth. Their importance in congenital heart disease. Circulation. 1970 Feb;41(2):343-59.

9. Renine JM. Examination of the newborn. In: Rennie JM, editor. Roberton's Textbook of Neonatology. 4th ed. Philadelphia: Churchill Livinstone; 2005. p. 249-66.

10. Poddar B, Basu S. Approach to a child with a heart murmur. Indian J Pediatr. 2004 Jan;71(1):63-6.

11. Ainsworth S, Wyllie JP, Wren C. Prevalence and clinical significance of cardiac murmurs in neonates. Arch Dis Child Fetal Neonatal Ed.1999Jan;80(1):F43-5.

12. Danilowicz DA, Rudolph AM, Hoffman JIE, Heymann M. Physiologic pressure differences between main and branch pulmonary arteries in infants. Circulation 1972;XLV:410- 19.

13. Silove ED. Assessment and management of congenital heart disease in the newborn by the district paediatrician. Arch Dis Child Fetal Neonatal Ed. 1994 Jan; 70 (1):F71-4.

14. Silverman ME, Wooley CF. Samuel A. Levine and the history of grading systolic murmurs. Am J Cardiol. 2008 Oct 15;102(8):1107-10.

15. Mirzarahimi M, Saadati H, Doustkami H, Alipoor $\mathrm{R}$, Isazadehfar $\mathrm{K}$, Enteshari A. Heart murmur in neonates: how often is it caused by congenital heart disease? Iran J Pediatr. 2011 Mar;21(1):103-6.

16. Park MK. Pediatric cardiology for practitioners. 5 th edition. Mosby. An Imprint of Elsevier; 2008:48-63.

17. Becker SM, Al Halees Z, Molina C, Paterson RM. Consanguinity and congenital heart disease in Saudi Arabia. Am J Med Genet. 2001 Feb 15;99(1):8-13.

18. Ramegowda S, Ramachandra NB. Parental consanguinity increases congenital heart diseases in South India. Ann Hum Biol. 2006 Sep-Dec;33(5-6): 519-28.
19. E. Clarke, M.R. Kumar. Evaluation of suspected congenital heart disease in the neonatal period. Current Paediatrics. 2005:15(7):523-531.

20. Swenson JM, Fischer DR, Miller SA, Boyle GJ, Ettedgui JA, Beerman LB. Are chest radiographs and electrocardiograms still valuable in evaluating new pediatric patients with heart murmurs or chest pain? Pediatrics. 1997 Jan;99(1):1-3.

21. Preethi S. Pillai, Neelima Narayanan, Lyla Chacko. An evaluation of cardiac murmurs in new-born. Int $\mathrm{J}$ Contemp Pediatr. 2017 Sep;4(5):1652-1657.

22. Hussain S, Sabir MU, Afzal M, Asghar I. Incidence of congential heart disease among neonates in a neonatal unit of a tertiary care hospital. Journal of the Pakistan Medical Association 2014; 64(2):175-8.

23. Yang Xue-yong, LI Xiao-feng, LU Xiao-dong, LIU Ying-long. Incidence of congenital heart disease in Beijing, China. Chinese Medical Journal 2009; 122(10): 1128-32.

24. Samitha R, Karat SC, Narayanappa D, Krishnamurthy B, Prasanth SN, Ramachandra NB. Prevalence of congenital heart diseases in Mysore. Indian Journal of Human Genetics 2006; 12 (2): 11-16.

25. B. S. Chakravathy, S. Prathimadevi. Evaluation of cardiac murmurs in neonates. $\mathrm{J}$ of evidence based med $\&$ health care 2015. Oct. Vol. 2 (42) p-7477-83. DOI: 10.18410/jebmh/2015/1010.

26. K F M Ferrer and J M Rennie Neonatal murmurs: are senior house officers good enough? Archives of Disease in childhood Fetal and Neonatal Edition 2003: 88:F147-150.

27. Moss S, Kitchiner DJ, Yoxall CW, Subhedar NV. Evaluation of echocardiography on the neonatal unit. Arch Dis Child Fetal Neonatal Ed. 2003 Jul;88 (4): F287-9; discussion F290-1.

\section{How to cite this article?}

Saranya R, Sampath Kumar D, Shankar R. A study on clinical and echo cardiographic evaluation of neonatal cardiac murmurs and their follow up at 6 weeks of age. Int J Pediatr Res. 2018;5(4):215-221. doi:10.17511/ijpr.2018.i04.10. 